\title{
A new hyhbrid coefficient of conjugate gradient method
}

\author{
Nur Syarafina Mohamed ${ }^{1}$, Mustafa Mamat ${ }^{2}$, Mohd Rivaie $^{3}$, Shazlyn Milleana Shaharudin ${ }^{4}$ \\ ${ }^{1}$ Universiti Kuala Lumpur, Malaysian Institute of Industrial Technology, Malaysia \\ ${ }^{2}$ Faculty of Informatics and Computing, Universiti Sultan Zainal Abidin (Unisza), Malaysia \\ ${ }^{3}$ Department of Computer Sciences and Mathematics, Universiti Teknologi MARA (UiTM) Terengganu, Malaysia \\ ${ }^{4}$ Department of Mathematics, Faculty of Science and Mathematics, Universiti Pendidikan Sultan Idris, Malaysia
}

\begin{tabular}{lll}
\hline \hline Article Info & ABSTRACT \\
\cline { 3 - 3 } Article history: & $\begin{array}{l}\text { Hybridization is one of the popular approaches in modifying the conjugate } \\
\text { gradient method. In this paper, a new hybrid conjugate gradient is suggested } \\
\text { Received Sep 15, } 2019 \\
\text { Revised Dec 1, 2019 }\end{array}$ & $\begin{array}{l}\text { and analyzed in which the parameter } \beta_{k} \text { is evaluated as a convex combination } \\
\text { of } \beta_{k}^{R M I L} \text { while using exact line search. The proposed method is shown to } \\
\text { possess both sufficient descent and global convergence properties. Numerical } \\
\text { performances show that the proposed method is promising and has } \\
\text { overpowered other hybrid conjugate gradient methods in its number of } \\
\text { Keywords: }\end{array}$ \\
iterations and central processing unit per time.
\end{tabular}

Exact line search

Hybrid conjugate gradient

method

Copyright $\odot 2020$ Institute of Advanced Engineering and Science. All rights reserved.

\section{Corresponding Author:}

Nur Syarafina Mohamed,

Malaysian Institute of Industrial Technology

Universiti Kuala Lumpur, Johor Bharu, Malaysia.

Email: nursyarafina@unikl.edu.my

\section{INTRODUCTION}

In unconstrained optimization, consider the following objective function;

$$
\min \left\{f(x): x \in R^{n}\right\}
$$

where $f: R^{n} \rightarrow R$ is a continuously differentiable function which is bounded from below and $R^{n}$ denotes as $n$-dimensional Euclidean space [1-3]. Generally, with any $x_{0} \in R^{n}$ as an initial guess, a sequence $\left\{x_{k}\right\}$ is generated by employing the CG iterative method given by;

$$
x_{k+1}=x_{k}+\alpha_{k} d_{k}, \quad k=0,1,2, \ldots
$$

where $x_{k}$ is the $k^{\text {th }}$ iterative point and $\alpha_{k}>0$ is a step size while the search direction $d_{k}$ is defined by;

$$
d_{k}=\left\{\begin{array}{lcc}
-g_{k} & \text { if } & k=0 \\
-g_{k}+\beta_{k} d_{k-1} & \text { if } & k \geq 1
\end{array}\right.
$$


The scalar $\beta_{k}$ is called the coefficient of CG and $g_{k}$ is the gradient of $f$ at point $x_{k}$. Step size $\alpha_{k}>0$ is the stepsize determined by using exact line search, given as;

$$
f\left(x_{k}+\alpha_{k} d_{k}\right)=\min _{\alpha \geq 0} f\left(x_{k}+\alpha d_{k}\right) \text {. }
$$

In the study of CG methods, a lot of modifications have been made but it is lacking in term of its superior. This study proposed a new method to outperform the number of iteration and CPU time compared to the previous coefficients. Hybrid CG method is known to be a combination of some classical CG methods combining the good criterion. In this paper, a new approach is suggested in order to get a new hybrid conjugate gradient algorithm. The new algorithm is a result from combining RMIL and SMR conjugate algorithms. Under exact line search, SMR has good computational properties while RMIL has strong convergence properties [1-2]. All the good criteria were combined in order to obtain a better practical algorithm. Section two will discuss the motivation of the algorithm and the new hybrid conjugate gradient algorithm. Section three presents the convergence analysis. Numerical experiments are discussed at section four and the last section concludes all the works in this paper.

\section{LITERATURE REVIEW}

The exact line search is well known to provide the optimal step size [4]. Recent studies have shown that the newer technologies with faster processors and better equipment have successfully eliminated the speed problems often suffered by exact line search as demonstrated by Rivaie et al [1]. This motivates plenty of its applications for solving unconstrained optimization problems. Different conjugate gradient method yield different choices for calculating the $\mathrm{CG}$ coefficient $\beta_{k}$. Some well known formulas for $\beta_{k}$ are;

$$
\begin{aligned}
& \beta_{k}^{H S}=\frac{g_{k}^{T}\left(g_{k}-g_{k-1}\right)}{\left(g_{k}-g_{k-1}\right)^{T} d_{k-1}} \\
& \beta_{k}^{F R}=\frac{g_{k}^{T} g_{k}}{\left\|g_{k-1}\right\|^{2}} \\
& \beta_{k}^{P R P}=\frac{g_{k}^{T}\left(g_{k}-g_{k-1}\right)}{\left\|g_{k-1}\right\|^{2}} \\
& \beta_{k}^{C D}=\frac{g_{k}^{T} g_{k}}{d_{k-1}^{T} g_{k-1}} \\
& \beta_{k}^{L S}=\frac{g_{k}^{T}\left(g_{k}-g_{k-1}\right)}{-d_{k-1}^{T} g_{k-1}} \\
& \beta_{k}^{R M I L}=\frac{g_{k}^{T}\left(g_{k}-g_{k-1}\right)}{\left\|d_{k-1}\right\|^{2}} \\
& \left(g_{k}-g_{k-1}\right)^{T} d_{k-1}
\end{aligned}
$$




$$
\beta_{k}^{S M R}=\max \left\{0, \frac{\left\|\mathrm{g}_{\mathrm{k}}\right\|^{2}-\left|g_{k}^{T} g_{k-1}\right|}{\left\|d_{k-1}\right\|^{2}}\right\}
$$

From (7)-(13), $g_{k}$ and $g_{k-1}$ are the abbreviations of $g\left(x_{k}\right)$ and $g\left(x_{k-1}\right)$ which are the gradients of $f(x)$ at points $x_{k}$ and $x_{k-1}$ respectively. Euclidean norm of the vectors is denoted by \|.\|. The above corresponding methods are known as HS (Hestenes and Steifel [5]), FR (Fletcher and Reeves [6]), PRP (Polak and Ribierre [7]), CD (Conjugate Descent by Fletcher [8]), DY (Dai and Yuan [9]), RMIL (Rivaie, Mustafa, Ismail and Leong [1]), SMR (Syarafina, Mustafa and Rivaie [2]) and LS (Liu-Storey [10]) respectively. All of these methods have finite convergence properties under exact line search due to strictly convex quadratic function $f(x)$. From all the methods mentioned above, some of these such as (8), (10) and (11) have strong convergence properties but not excellent in practical performance due to jamming problem. Meanwhile, methods in (7), (9) and (13) have better performance though lacking in convergence properties [11]. Conjugate gradient method can be classified into three different groups; classical, scaled and hybrid CG method [12]. Due to their simple approach, CG methods in (7) - (14) are said to be classical. Detailed discussions are available in [13-24].

In this paper, the main objective is to focus on hybrid conjugate gradient method. The idea is to combine different conjugate algorithms to use the projections to form a new hybrid convex-combination algorithm in order to avoid jamming [11]. Early hybrid conjugate gradient algorithm was first proposed by Touati-Ahmed and Storey [25]. Some well known hybrid conjugate algorithms are;

$$
\begin{aligned}
& \beta_{k}^{H D Y}=\max \left\{0, \min \left\{\beta_{k}^{H S}, \beta_{k}^{D Y}\right\}\right\} \\
& \beta_{k}^{H H U S}=\max \left\{0, \min \left\{\beta_{k}^{P R P}, \beta_{k}^{F R}\right\}\right\} \\
& \beta_{k}^{H L S C D}=\max \left\{0, \min \left\{\beta_{k}^{L S}, \beta_{k}^{C D}\right\}\right\} \\
& \beta_{k}^{H J H J}=\frac{\left\|g_{k}\right\|^{2}-\max \left\{0, \frac{\left\|g_{k}\right\|}{\left\|g_{k-1}\right\|} g_{k}^{T} g_{k-1}\right\}}{\max \left\{\left\|g_{k-1}\right\|^{2}, d_{k-1}^{T}\left(g_{k}-g_{k-1}\right)\right\}}
\end{aligned}
$$

From (15)-(18) HDY is a modification effort from Dai and Yuan [9] combining its algorithm with Hestenes and Steifel [5], HHUS was introduced by Hu and Storey [26], HLSCD is the combination of LS [10] and CD [8] and HJHJ is a hybrid CG from Jinbao-Han-Jiang [27]. From (18), it is easy to know the algorithm is a combination of various classical CG methods [28-30].

\section{NEW HYBRID CG METHOD}

Motivated by the idea of combining various CG algorithm from (15)-(18), a new hybrid coefficient is proposed between RMIL [1] and SMR [2] where the methods are respectively known by (12) and (14). The new coefficient introduced is as follows;

$$
\beta_{k}^{H S M R}=\max \left\{0, \min \left\{\beta_{k}^{S M R}, \beta_{k}^{R M I L}\right\}\right\}
$$

where HSMR stands for Hybrid-Syarafina-Mustafa-Rivaie method. This new method is suggested due to the restart strategy proposed in [31]. It is suitable to set $\beta_{k}=0$, which implies a restart along $g_{k}$. If $\beta_{k}<0$, the search direction $d_{k}$ from (3) tend to almost opposite to $d_{k-1}$. By restricting the CG coefficient to $\beta_{k} \geq 0$ the two consecutive search directions are prevented from tending to be almost opposite [32]. The new algorithm of $\beta_{k}^{H S M R}$ is given as follows; 


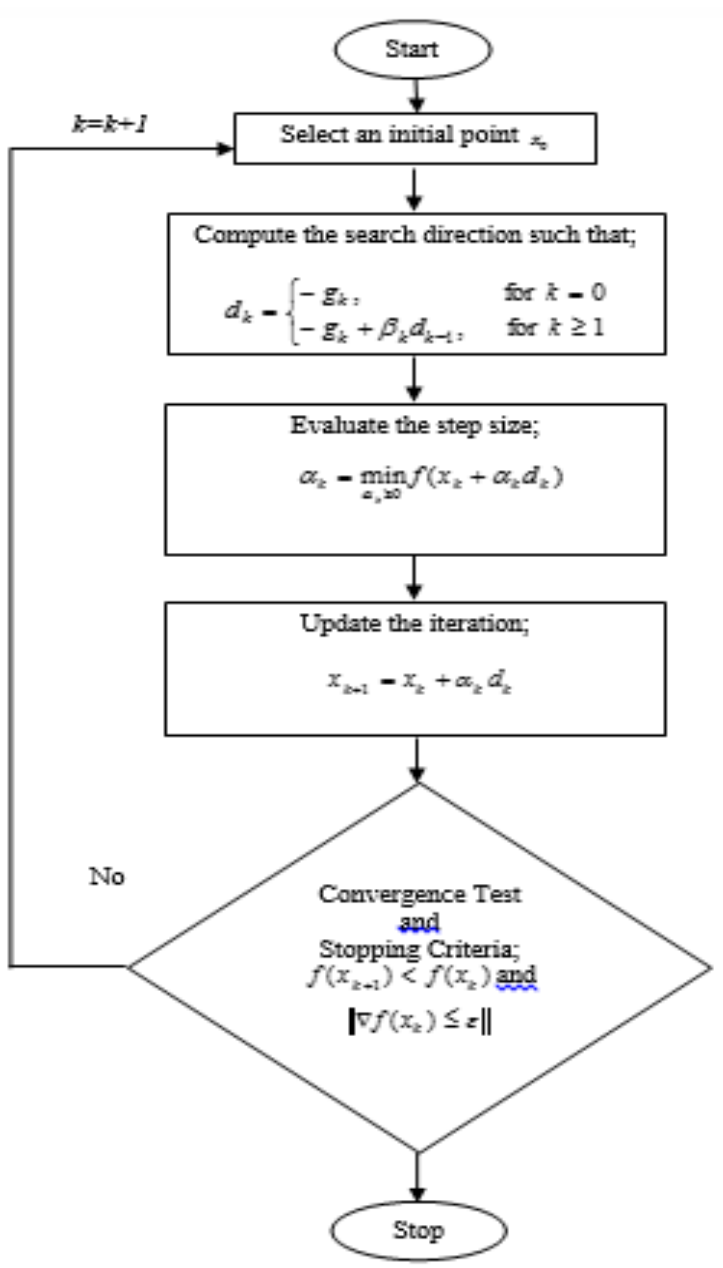

Figure 1. Conjugate Gradient Algorithm

Algorithm 2.1: Conjugate Gradient Algorithm

A complete algorithm of CG method could be generated as follows:

Step 1: Initialization. Set $k=0$ and select $x_{0} \in \mathfrak{R}^{n}, d_{0}=-g_{0}$, if $g_{0}=0$, stop.

Step 2: Compute $\beta_{k}^{H S M R}$ based on (19).

Step 3: Compute search directions $d_{k}$ based on (3). If $\left\|g_{k}\right\| \leq \varepsilon$, then stop. Otherwise, go to the next step.

Step 4: Compute for $\alpha_{k}$ based on exact line search (4).

Step 5: Updating new initial point using (2).

Step 6: Convergence test and stopping criteria. If $f\left(x_{k+1}\right)<f\left(x_{k}\right)$ and $\left\|g_{k}\right\| \leq \varepsilon$ then, stop. Otherwise go to Step 2 with $k=k+1$.

\section{CONVERGENCE ANALYSIS}

In this section, the convergence analysis based on exact line search in (4) is analysed. An algorithm has to possess both sufficient descent condition and global convergence properties for a method to be converged.

\subsection{Sufficient Descent Condition}

Sufficient descent condition holds when

$$
g_{k}^{T} d_{k} \leq-C\left\|g_{k}\right\|^{2} \text { for } k \geq 0 \text { and } C>0
$$


Theorem 1: Consider a CG method with search direction (3) and $\beta_{k}^{H S M R}$ defined as (19), then, condition (20) will hold for all $k \geq 0$. Proof: From (3), know that $g_{0}^{T} d_{0}=-C\left\|g_{0}\right\|^{2}$. Hence, condition (20) holds. In order to show condition (20) also hold for $k \geq 1$, multiply (3) by $g_{k}^{T}$. Then,

$$
g_{k}^{T} d_{k}=-g_{k}^{T} g_{k}+\beta_{k}{ }^{H S M R} g_{k}^{T} d_{k-1}=-\left\|g_{k}\right\|^{2}+\beta_{k}{ }^{H S M R} g_{k}^{T} d_{k-1}
$$

For $k=1$, it is easy to know that $g_{1}^{T} d_{1}=-\left\|g_{k}\right\|^{2}<0$. Assume that $g_{k-1}^{T} d_{k-1}<0$ holds for $k-1$ and $k \geq 2$. To prove that $g_{k}^{T} d_{k}<0$ for all $k$, consider these two cases:

CASE I: If $\beta_{k}^{R M I L}=\frac{g_{k}^{T}\left(g_{k}-g_{k-1}\right)}{\left\|d_{k-1}\right\|^{2}}<0$, automatically $\beta_{k}^{H S M R}$ return to 0 such that $\beta_{k}^{S M R} \geq 0$. When $\beta_{k}^{H S M R}=0$, it is known that $g_{k}^{T} d_{k}=-\left\|g_{k}\right\|^{2}<0$.

CASE II: If $\beta_{k}^{R M I L}=\frac{g_{k}^{T}\left(g_{k}-g_{k-1}\right)}{\left\|d_{k-1}\right\|^{2}} \geq 0$, then, $\beta_{k}^{H S M R} \neq 0$ and can either be $\beta_{k}^{S M R}$ or $\beta_{k}^{R M I L}$.

Since the line search is exact, it is known that $g_{k}^{T} d_{k-1}=0$. Thus, $g_{k}^{T} d_{k}=-\left\|g_{k}\right\|^{2}$ implying $d_{k}$ is a sufficient descent direction. Hence, the descent condition holds i.e., $g_{k}^{T} d_{k} \leq-C\left\|g_{k}\right\|^{2}$. The proof is completed.

\subsection{Global Convergence Properties}

From [1] and [2], it is known that $\beta_{k}^{S M R}$ and $\beta_{k}^{R M I L}$ can be simplified to:

$$
0 \leq \beta_{k+1} \leq \frac{\left\|g_{k+1}\right\|^{2}}{\left\|d_{k}\right\|^{2}}
$$

Case II stated that $\beta_{k}^{H S M R}$ and can either be $\beta_{k}^{S M R}$ or $\beta_{k}^{R M I L}$ if $\beta_{k}^{R M I L}=\frac{g_{k}^{T}\left(g_{k}-g_{k-1}\right)}{\left\|d_{k-1}\right\|^{2}} \geq 0$. Then, from $[1,2]$ and [18], in the analysis of global convergence properties, the following assumption is needed.

\section{Assumption 1}

1. $f$ is bounded below on the level set $R^{n}$ and is continuous and differentiable in a neighbourhood $N$ of the level set $\ell=\left\{x \in R^{n} \mid f(x) \leq f\left(x_{0}\right)\right\}$ at the initial point $x_{0}$.

2. The gradient $g(x)$ is Lipschitz continuous in $N$, so, there exists a constant $L>0$ such that; $\|g(x)-g(y)\| \leq L\|x-y\|$ for any $x, y \in N$.

Under this assumption, the following lemma is obtained, which was proved by Zoutendijk [33].

Lemma 1: Suppose that Assumption 1 holds. Consider any CG methods of the form (3) where $d_{k}$ is a descent search direction and $\alpha_{k}$ satisfies the exact minimization rules. Then the following conditions known as Zoutendijk conditions hold;

$$
\sum_{k=0}^{\infty} \frac{\left(g_{k}^{T} d_{k}\right)^{2}}{\left\|d_{k}\right\|^{2}}<\infty .
$$

The proof of this lemma can be seen from [25].By using this lemma; the following convergence theorem of the conjugate gradient method can be obtained by using (22).

Theorem 1: Suppose that Assumption 1 holds. Consider any CG methods in the form of (3) and (2) where $\alpha_{k}$ is obtained by the exact minimization rules. Also, suppose that Assumption 1 and the descent condition hold. Then either: 


$$
\lim _{k \rightarrow \infty}\left\|g_{k}\right\|=0 \quad \text { or } \quad \sum_{k=0}^{\infty} \frac{\left(g_{k}^{T} d_{k}\right)^{2}}{\left\|d_{k}\right\|^{2}}<\infty .
$$

Proof: By induction, if Theorem 1 is not true then, there exists a constant $c>0$ such that:

$$
\left\|g_{k}\right\| \geq c
$$

Rewriting (3) and squaring both sides, we get:

$$
\left\|d_{k+1}\right\|^{2}=\left(\beta_{k+1}\right)^{2}\left\|d_{k}\right\|^{2}-2 g_{k+1}^{T} d_{k+1}-\left\|g_{k+1}\right\|^{2}
$$

Using $\left(g_{k+1}^{T} d_{k+1}\right)^{2}$ and dividing both sides,

$$
\frac{\left\|d_{k+1}\right\|^{2}}{\left(g_{k+1}^{T} d_{k+1}\right)^{2}}=\frac{\left(\beta_{k+1}\right)^{2}\left\|d_{k}\right\|^{2}}{\left(g_{k+1}^{T} d_{k+1}\right)^{2}}-\frac{2}{g_{k+1}^{T} d_{k+1}}-\frac{\left\|g_{k+1}\right\|^{2}}{g_{k+1}^{T} d_{k+1}}
$$

By completing the square, the equation becomes:

$$
=\frac{\left(\beta_{k+1}\right)^{2}\left\|d_{k}\right\|^{2}}{\left(g_{k+1}^{T} d_{k+1}\right)^{2}}-\left(\frac{1}{\left\|g_{k+1}\right\|}+\frac{\left\|g_{k+1}\right\|}{g_{k+1}^{T} d_{k+1}}\right)^{2}+\frac{1}{\left\|g_{k+1}\right\|^{2}} \leq \frac{\left(\beta_{k+1}\right)^{2}\left\|d_{k}\right\|^{2}}{\left(g_{k+1}^{T} d_{k+1}\right)^{2}}+\frac{1}{\left\|g_{k+1}\right\|^{2}}
$$

Applying (22), yields

$$
=\left(\frac{\left\|g_{k+1}\right\|^{2}}{\left\|d_{k}\right\|^{2}}\right)^{2} \frac{\left\|d_{k}\right\|^{2}}{\left(g_{k+1}^{T} d_{k+1}\right)^{2}}+\frac{1}{\left\|g_{k+1}\right\|^{2}}=\frac{\left\|g_{k+1}\right\|^{2}}{\left\|d_{k}\right\|^{2}\left\|d_{k+1}\right\|^{2}}+\frac{1}{\left\|g_{k+1}\right\|^{2}} \leq \frac{1}{\left\|d_{k}\right\|^{2}}+\frac{1}{\left\|g_{k+1}\right\|^{2}}
$$

From (25), noting that:

$$
\frac{1}{\left\|d_{0}\right\|^{2}}=\frac{1}{\left\|g_{0}\right\|^{2}}
$$

then,

$$
\frac{\left\|d_{k}\right\|^{2}}{\left(g_{k} d_{k}\right)^{2}}=\frac{1}{\left\|g_{0}\right\|^{2}}+\frac{1}{\left\|g_{k}\right\|^{2}}
$$

Hence,

$$
\frac{\left\|d_{k}\right\|^{2}}{\left(g_{k} d_{k}\right)^{2}} \leq \sum_{i=0}^{k} \frac{1}{\left\|g_{i}\right\|^{2}} \text { and } \frac{\left(g_{k} d_{k}\right)^{2}}{\left\|d_{k}\right\|^{2}} \geq \frac{c^{2}}{k}
$$

Then, from (23) and (25), it follows; $\sum_{k=0}^{\infty} \frac{\left(g_{k}^{T} d_{k}\right)^{2}}{\left\|d_{k}\right\|^{2}}=\infty$. This contradicts the Zoutendijk condition in Lemma 1. Therefore the proof is completed.

Corollary 1: If $\sum_{k=0}^{\infty}\left\|d_{k}\right\|^{2}=0$, then $\sum_{k=0}^{\infty} \frac{\left(g_{k}^{T} d_{k}\right)^{2}}{\left\|d_{k}\right\|^{2}}<\infty$ holds. 
Proof: By using contradiction, assume that $\left\|g_{k}\right\| \geq c$ and $\sum_{k=0}^{\infty}\left\|d_{k}\right\|^{2}=\infty$. For $\left\|g_{k}\right\| \rightarrow \infty$, then, $\frac{1}{\left\|g_{k}\right\|} \rightarrow 0$. From (25),

$$
\frac{\left\|d_{k}\right\|^{2}}{\left(g_{k}^{T} d_{k}\right)^{2}} \leq \frac{1}{\left\|d_{k}\right\|^{2}}
$$

then,

$$
\left\|d_{k}\right\|^{2} \leq \frac{\left(g_{k}^{T} d_{k}\right)^{2}}{\left\|d_{k}\right\|^{2}}
$$

Which leads to, $\sum_{k=0}^{\infty}\left\|d_{k}\right\|^{2} \leq \sum_{k=0}^{\infty} \frac{\left(g_{k}^{T} d_{k}\right)^{2}}{\left\|d_{k}\right\|^{2}}$ and $\infty \leq \sum_{k=0}^{\infty} \frac{\left(g_{k}^{T} d_{k}\right)^{2}}{\left\|d_{k}\right\|^{2}}$.

This contradicts the Zoutendijk conditions. Hence the corollary holds.

\section{NUMERICAL RESULTS AND DISCUSSION}

This section presents the numerical performance of the new coefficient $\beta_{k}^{H S M R}$ compared with other coefficients mentioned in (15)-(18). A list of fifteen small to large-scale unconstrained optimization test functions considered in Andrei [34] was selected as shown in Table 1. A large-scaled problem is chosen in order to detect a cynical observer preventing the algorithm being tuned in particular functions [35]. In this paper, four random initial starting points are chosen for each of test functions used to add to the complexity of the computer programming [36]. Points chosen can also be used to test the global convergence properties and the robustness of the methods. Results analyses are based on MATLAB subroutine programme on workstation Intel Core i7, $2.2 \mathrm{GHz}$ tested on number of iterations and central processing time per unit. The stopping criterion is set to $\left\|g_{k}\right\| \leq 10^{-6}$, where $\varepsilon=10^{-6}$. Performance profiles based on Dolan and More [37] are shown graphically in Figures 1-2 [38-39]

\begin{tabular}{|c|c|c|c|}
\hline No & Function & $n$ & Initial Points \\
\hline 1 & 3-Hump & 2 & $(-1,1),(1,-1),(-2,2),(2,-2)$ \\
\hline 2 & 6-Hump & 2 & $(8,8),(-8,-8),(10,10),(-10,-10)$ \\
\hline 3 & Booth & 2 & $(10,10),(25,25),(50,50),(100,100)$ \\
\hline 4 & Treccani & 2 & $(5,5),(10,10),(50,50),(100,100)$ \\
\hline 5 & Goldstein-Price & 2 & $(2,-2),(5,-5),(10,-10),(13,-13)$ \\
\hline 6 & $\begin{array}{l}\text { Extended } \\
\text { Himmelblau }\end{array}$ & $2,4,10,100,500,1000$ & $(10,10, . .10),(50,50,, 50),(100,100,, 100),(200,200,, 200)$ \\
\hline 7 & Extended Denschnb & $2,4,10,100,500,1000$ & $(5,5, \ldots, 5),(8,8, \ldots, 8),(13,13, \ldots, 13),(25,25, \ldots, 25)$ \\
\hline 8 & Generalized Quartic & $2,4,10,100,500,1000$ & $(10,10,, 10),(50,50,, 50),(100,100,, 100),(200,200,, 200)$ \\
\hline 9 & Diagonal 4 & $2,4,10,100,500,1000$ & $(10,10,10),(50,50,, 50),(100,100, \ldots 100),(200,200, \ldots 200)$ \\
\hline 10 & $\begin{array}{c}\text { Extended } \\
\text { Freundestein and } \\
\text { Roth }\end{array}$ & $2,4,10,100,500,1000$ & $(1,1, \ldots, 1),(3,3, \ldots, 3),(5,5, \ldots, 5),(7,7, \ldots, 7)$ \\
\hline 11 & $\begin{array}{l}\text { Extended } \\
\text { Rosenbrock }\end{array}$ & $2,4,10,100,500,1000$ & $(13,13, \ldots, 13),(16,16, \ldots, 16),(20,20, \ldots, 20),(30,30, \ldots, 30)$ \\
\hline 12 & $\begin{array}{l}\text { Extended } \\
\text { Tridiagonal } 1\end{array}$ & $2,4,10,100,500,1000$ & $(10,10, \ldots, 10),(12,12, \ldots, 12),(17,17, \ldots, 17),(20,20, \ldots, 20)$ \\
\hline 13 & Shalow & $2,4,10,100,500,1000$ & $(10,10, \ldots, 10),(25,25, \ldots, 25)(50,50, \ldots, 50),(100,100, \ldots, 100)$ \\
\hline 14 & Extended Beale & $2,4,10,100,500,1000$ & $(1,1, \ldots, 1),(-1,-1, \ldots,-1),(3,3, \ldots, 3),(2,2, \ldots, 2)$ \\
\hline 15 & Fletchr & $2,4,10,100,500,1000$ & $(2,2, \ldots, 2),(3,3, \ldots, 3),(5,5, \ldots, 5),(7,7, \ldots, 7)(9,9, \ldots, 9)$ \\
\hline
\end{tabular}

Table 1. List of test functions

The $P_{s}(t)$ from the performance profile is the fraction of problem with a ratio performance $t$.A solver has higher efficiency when its value of $P_{S}(t)$ is higher. In a set of problem $P$ and a set of optimization solve 
$S$, a performance comparison of problem $p \in P$ by a particular algorithm $s \in S$ is measured. Let, $t_{p, s}$ be the number of iterations or CPU time required when solving a problem $p \in P$ with solver $s \in S$. The performance ratio is defined by $r_{p, s}=\frac{t_{p, s}}{\min \left\{t_{p, s}: s \in S\right\}}$. From this expression, it is assumed that $r_{p, s} \in\left[1, r_{M}\right]$, where $r_{M} \geq r_{p, s}$ and $r_{p, s}=r_{M}$ only when problem $p$ is not solved by solver $S$. Then, graphically, a graph of $P_{S}(t)$ versus $t \in\left[1, r_{M}\right]$ is plotted. In a graph of performance profile, the smallest performance ratio is 1 and it will be located at the most left of $t$ - axis, hence, the top curve represents the most efficient method.

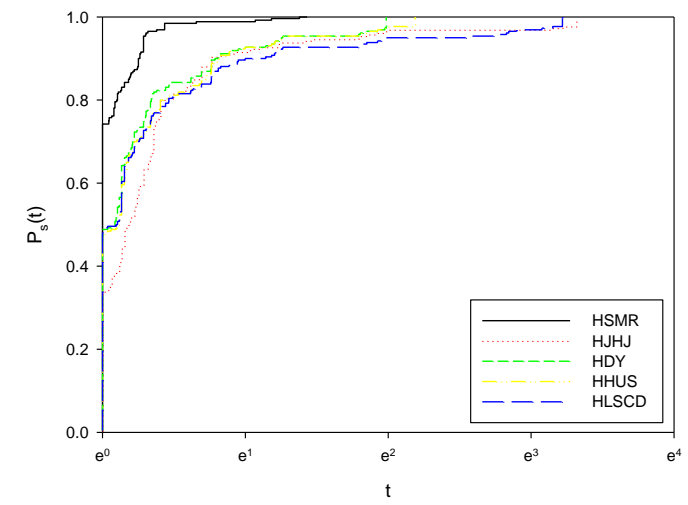

Figure 1. Performance profile based on number of iterations

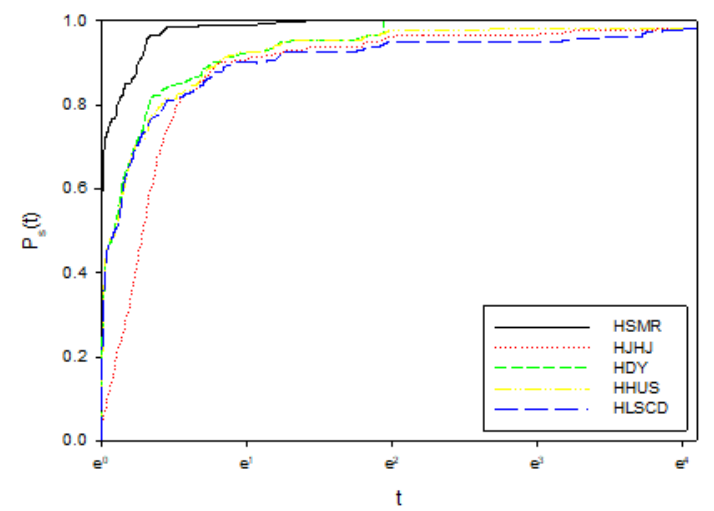

Figure 2. Performance profile based on CPU time

Figure 1 and Figure 2 show the performance of the CG coefficients based on number of iterations and central processing time per unit respectively for exact line search. The top left curved indicated how fast the coefficient converge while the top right determine how many test functions can be tested on given coefficient. From both figures, it is clearly indicate that the new hybrid $\beta_{k}^{H S M R}$ outperformed the other hybrid CG coefficients.

\section{CONCLUSION}

In this paper, a new hybrid of $\mathrm{CG}$ algorithm $\beta_{k}^{H S M R}$ is proposed and examined for solving unconstrained optimization problem. Proofs showed that the algorithm satisfies the convergence properties globally under descent conditions by using exact line search. Numerical results have shown that the new algorithm proposed is competitive and performs better than HJHJ, HDY, HHUS and HLSCD. In the future, the new algorithm is going to be tested under different search rules.

\section{ACKNOWLEDGEMENTS}

The authors are very grateful to the editors and the anonymous reviewers for their valuable comments and suggestions which improved this paper substantially.

\section{REFERENCES}

[1] M. Rivaie, M. Mamat, L. W. June, and I. Mohd, “A new class of nonlinear conjugate gradient coefficients with global convergence properties,” Appl. Math. Comp. vol. 218, pp. 11323-11332. 2012.

[2] N. S. Mohamed, M. Mamat, and M. Rivaie, "A new coefficient of conjugate gradient methods for nonlinear unconstrained optimization,”Jurnal Teknologi. vol. 78, no. 6-4, pp. 131-136. 2016.

[3] M. Rivaie, M. Mamat and A. Abashar, "A new class of nonlinear conjugate gradient coefficients with exact and inexact line searches," Appl. Math. Comp. vol. 268, 1152-1163. 2015.

[4] M. A. H. Ibrahim, M. Mamat and L. W. June, "BFGS method: a new search direction," Sains Malaysia. vol. 43, no. 10, pp. 1591-1597. 2014. 
[5] M. R. Hestenes and E. Steifel, J. Res. "Methods of conjugate gradients for solving linear systems," Nat. Bur. Stand, vol. 49, pp. 409-436. 1952.

[6] R. Fletcher and C. Reeves, "Methods of conjugate gradients for solving linear systems," Computational Journal, vol. 7, pp. 149-154. 1964.

[7] E. Polak, and G. Ribiere, "Note sur la convergence de méthodes de directions conjuguées," Rev. Francaise Informat Recherche Operationelle, 3E Annee, vol. 16, pp.35-43. 1969.

[8] R. Fletcher, "Practical Methods of Unconstrained Optimization," J. Wiley and Sons, New York, 1987.

[9] Y. H. Dai, and Y. Yuan, "A Nonlinear Conjugate Gradient Method with a Strong Global Convergence Property," SIAM Journal Optimization, vol. 10, pp. 177-182. 2000.

[10] Y. Liu, C. Storey, "Hybrid Conjugate Gradient Algorithm for Unconstrained Optimization,"J. Optim. Theory Appl. vol. 69, pp.129-137. 1991.

[11] N. Andrei, "Hybrid Conjugate Gradient Algorithm for Unconstrained Optimization," J. Optim. Theory. Appl. vol. 141, pp. 249-264. 2009.

[12] N. Andrei, “Open problems in nonlinear conjugate gradient algorithms for unconstrained optimization," Bull. Malay. Math. Sci. Soc. vol. 34, pp. 319-330. 2011.

[13] S. Syazni, M. Rivaie and M. Mamat, "A Modification of Classical Conjugate Gradient Method using Strong Wolfe line search," AIP Conference Proceeding 1739, American Institute of Physics, Melville, NY, 2016.

[14] A. A. Abderahman, M. Mamat, M. Rivaie, and O. Omer, "The Proof of Sufficient Descent Condition for a New Type of Conjugate Gradient Methods," AIP Conference Proceedings 1602, American Institute of Physics, Melville, NY, 2014, pp-296.

[15] N. Hajar, M. Mamat, M. Rivaie, and Z. Salleh, "A combination of Polak-Ribiere and Hestenes-Steifel coefficient in conjugate gradient method for unconstrained optimization," Applied Mathematical Sciences, vol. 9, no. 63, pp.31313142. 2015.

[16] M. Hamoda, M. Mamat, M. Rivaie, and Z. Salleh, "A conjugate gradient method with strong Wolfe-Powell line search for unconstrained optimization," Applied Mathematical Science, vol. 10, no. 15, pp. 721-734. 2016.

[17] M. Rivaie, A. Abderahman, M. Mamat, and I. Mohd, "The convergence properties of a new type of conjugate gradient methods," Applied Mathematical Sciences, vol. 8, no. 1, pp.33-34. 2014.

[18] N. S. Mohamed, M. Mamat, and M. Rivaie, "Solving a Large Scale Nonlinear Unconstrained Optimization with Exact Line Search Direction by Using New Coefficient of Conjugate Gradient Methods," AIP Conference Proceeding 1787, American Institute of Physics, Melville, NY, 2016.

[19] N. Shapiee, M. Rivaie, and M. Mamat, "A New Classical Conjugate Gradient Coefficient with Exact Line Search," AIP Conference Proceedings 1739, American Institute of Physics, Melville, NY, 2016.

[20] Z. Z. Abidin, M. Mamat, M. Rivaie, and I. Mohd, “A New Steepest Descent Method," AIP Conference Proceedings 1602, American Institute of Physics, Melville, NY, 2014.

[21] A. Abdelrahman, "A New Type of Conjugate Gradient Methods with Sufficient Descent Property for Unconstrained Optimizations," Ph.D. thesis, Universiti Malaysia Terengganu, 2014.

[22] I. Jusoh, "New Family of Conjugate Gradient Methods with Sufficient Descent Condition and Global Convergence for Unconstrained Optimizations," Ph.D. thesis, Universiti Sultan Zainal Abidin, 2015.

[23] N. Hamizah, M. Rivaie, and M. Mamat, "A Modified Form of Conjugate Gradient Method for Unconstrained Optimization Problems,” AIP Conference Proceedings 1739, American Institute of Physics, Melville, NY, 2016.

[24] N. Aini, M. Mamat, and M. Rivaie, "A modified Conjugate Gradient Coefficient with Inexact Line Searchfor Unconstrained Optimization, " AIP Conference Proceeding 1787, American Institute of Physics, NY, 2016).

[25] D. Touati-Ahmed, C. Storey, C. "Efficient hybrid conjugate gradient techniques," J. Optim. Theory Appl. vol. 64, pp. 379-397. 1990.

[26] Y. F. Hu,C. Storey. "Global convergence result for conjugate gradient methods," J. Optim. Theory. Appl. vol. 71, pp. 399-405. 1991.

[27] J. Jinbao, H. Lin, and J. Xianzhen, "A hybrid conjugate gradient method with descent property for unconstrained optimization," Applied Mathematical Modelling. 2014.

[28] Z. X. Wei, S.W. Yao, L.Y. Liu, "The convergence properties of some new conjugate gradient methods," Appl. Math. Computational. vol. 183, pp. 1341-1350. 2006.

[29] S.W. Yao, Z.X. Wei, H. Huang, "A note about WYL's conjugate gradient method and its application," Appl. Math. Computational. vol. 191, pp. 381-388. 2007.

[30] X. Z. Jiang, L. Han, J.B. Jian, "A globally convergent mixed conjugate gradient method with Wolfe line search," Math. Numer. Sin. vol. 34, pp. 103-112. 2012

[31] M. J. D. Powell, "Nonconvex minimization calculations and the conjugate gradient method," Notes in Mathematics, vol. 1066, pp. 122-141, Springer, Berlin, 1984.

Indonesian J Elec Eng \& Comp Sci, Vol. 18, No. 3, June 2020 : 1454 - 1463 
[32] Y.H. Dai and Y. Yuan, "An efficient hybrid conjugate gradient method for unconstrained optimization," Annals of Operating Research, vol. 103, pp. 33-47. 2001.

[33] G. Zoutendijk, Abadie J. Editors. Integer and Nonlinear Programming, pp. 37-86. 1970.

[34] N. Andrei, “An Unconstrained Optimization Test Functions Collection," Advanced Modelling and Optim. Vol. 10, no. 1. 2008.

[35] J. J. More, B. Garbow, and K. E. Hillstrom, Journal ACM Transaction on Mathematical Software, vol. 7, 1, pp. 1741. (1981).

[36] K.E. Hilstrom, "A Simulation Test Approach to the Evaluation of Nonlinear Optimization Algorithms," A.C.M. Trans. Maths. Softw. vol. 3, pp. 305-315. 1977.

[37] E. Dolan, J.J. More, "Benchmarking optimization software with performance profiles,” Maths. Prog. Ser. vol. 91, pp. 201-213. 2002.

[38] N. S. Mohamed, M. Mustafa, M. Rivaie, S. M. Shaharuddin, "Global Convergence of a New Coefficient Nonlinear Conjugate Gradient Method," Indonesian Journal of Electrical Engineeting and Computer Science, vol. 11, 3, 2018.

[39] S. M. Shaharuddin, N. Ahmad, N. H. Zainuddin, N. S. Mohamed, "Identification of Rainfall Patterns on Hydrological Simulation using Robust Prinicipal Component Analysis," Indonesian Journal of Electrical Engineeting and Computer Science, 11, 3, 2018.

\section{BIOGRAPHIES OF AUTHORS}

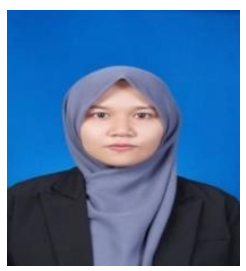

Nur Syarafina Mohamed is a Senior Lecturer in Universiti Kuala Lumpur specialized in Optimization area. She graduated with a bachelor science degree in Industrial Mathematics from Universiti Teknologi Malaysia, in 2010. Upon graduation, she began her career as a lecturer in Universiti Teknologi Mara from 2010 till 2016 in a contract basis. Arund 2013, she started her $\mathrm{PhD}$ journey in Universiti Sultan Zainal Abidin in Kuala Terenganu Malaysia. Her research interest is focused on Optimization where she modified the Cnjugate Gradient Method by implementing new adjustment on the coefficient used in the algorithm. The parameter introduced is compared among the best parameters which was introduced previously. She had published her research in Scopus indexed journal and presented her work in various local and international conferences. She completed her PhD thesis in April 2017 and was conferred a doctorate degree in December 2017.

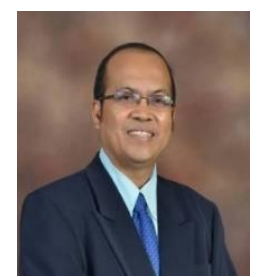

Mustafa Mamat is currently a Professor at Universiti Sultan Zainal Abidin (Unisza), Malaysia since 2013. He was first appointed as a lecturer at Universiti Malaysia Terengganu (UMT) in 1999. He obtained his Ph.D from UMT in 2007 specialization in optimization field. Later on, he was appointed as a Senior Lectures in 2008 and then as an Associate Professor in 2010 also at UMT. To date, he has successfully supervised more than 50 postgraduate students and published more than 170 research papers in various international journals and conferences. His research interest includes optimization, chaos and finite difference methods.

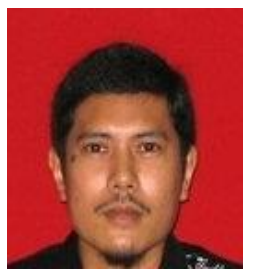

Mohd Rivaie Mohd Ali is a Senior Lecturer in Universiti Teknologi Mara specialized in Optimizationa area. He obtained his doctorate degree in Universiti Malaysia Terengganu supervised by Prof Dr Mustafa Mamat. He was conferred a doctorate degree since 2012 and since then, his research contributions increased year by year. Having more than 300 citations and around 100 research articles make him a specialist in his area which focused on Optimization.

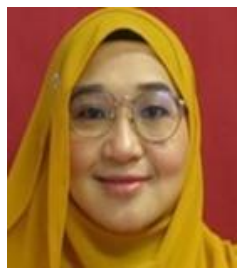

She is a senior lecturer at the Department of Mathematics, Faculty of Science and Mathematics, Universiti Pendidikan Sultan Idris (UPSI). She graduated with a bachelor science degree in Industrial Mathematics from Universiti Teknologi Malaysia, in 2010. Upon graduation, she began her career as an Executive in banking institution. In the following year, she received an offer to continue her study as a fast-track PhD student at the same university. During her PhD journey, she developed an interest in multivariate analysis, specifically in finding patterns which deals with big data. Her research focuses on the area of dimension reduction methods specifically in climate informatics which involves analysis on huge climate-related datasets based on techniques in Data Mining. She had published her research in Scopus indexed journal and presented her work in various local and international conferences. She completed her PhD thesis at the end of 2016 and was conferred a doctorate degree in 2017. 